\title{
Graft Copolymers Having Hydrophobic Backbone and Hydrophilic Branches XXXI. A DSC Study of Internal Structures and Thermophysical Properties of Core-Corona Polymeric Nanospheres
}

\author{
Ken-ichiro HiwatARI, Takeshi SeRIZAWA, Akio KISHIDA, and Mitsuru AKASHI $^{\dagger}$ \\ Department of Applied Chemistry and Chemical Engineering, Faculty of Engineering, Kagoshima University, \\ 1-21-40 Korimoto, Kagoshima 890-0065, Japan
}

(Received December 15, 2000; Accepted January 30, 2001)

\begin{abstract}
Polystyrene core nanospheres having poly(ethylene glycol) (PEG) polymers on the corona were prepared by the free radical polymerization of hydrophilic methacryloyl group terminated PEG macromonomer and hydrophobic styrene with AIBN as radical initiator in a ethanol/water $(4 / 1, \mathrm{v} / \mathrm{v})$ mixed solvent. The correlation between compositions of the nanospheres and thermal properties was studied by Differential Scanning Calorimetry (DSC). The glass transition temperature $\left(T_{\mathrm{g}}\right)$ of the poly(styrene-co-alkylmethacrylate) core of the nanospheres was constant at 90 to $100^{\circ} \mathrm{C}$, even though the chemical compositions of the nanospheres differed. The melting temperature $\left(T_{\mathrm{m}}\right)$ of the PEG in the nanospheres was lowered compared with PEG itself. The $T_{\mathrm{g}}$ of poly(styrene-co-alkylmethacrylate) in nanospheres composed of more PEG was lowered, although the $T_{\mathrm{m}}$ of the PEG in the nanospheres was higher than that of nanosphere containing small amounts of PEG. These results indicate that the thermal properties and compositions of the nanospheres were correlated. Freeze-dried nanospheres were annealed at $60^{\circ} \mathrm{C}$ for $30 \mathrm{~min}$ in flask under nitrogen atmosphere. After the annealing, spherical form of the nanospheres consisting of a high percentage of polystyrene was maintained, although the thermal properties dramatically changed by the thermal treatment. The $T_{\mathrm{g}}$ of the poly(styrene-coalkylmethacrylate) segment and the $T_{\mathrm{m}}$ of the PEG segment in the nanospheres were affected by composition of the graft copolymer and compatibility of the components of the graft copolymer.

KEY WORDS Nanospheres / Macromonomer Method / Core-Corona / Thermal Property / Internal Structure / Annealing /
\end{abstract}

The free radical dispersion copolymerization of hydrophilic macromonomers and hydrophobic comonomers in a polar solvent gave water dispersible polymeric particles by our "Macromonomer Method". "The particles called "core-corona nanospheres", and variety of polymeric particles have been prepared. ${ }^{2-4}$ Nanospheres assembled with functional groups on the surface are great scientific interest for various applications as foundations for catalyst, ${ }^{5}$ captures of human immununodeficiency virus-1 (HIV-1), ${ }^{6}$ and peptide drug carriers via oral administration. ${ }^{7-9}$ Using various polymers as macromonomers, such as poly( $N$-vinylisobutyramide)(PNVIBA) or poly(methacrylic acid)(PMAA) as a polyelectrolytes, thermosensitive or $\mathrm{pH}$ sensitive nanospheres were obtained. ${ }^{2-4,10}$

In the macromonomer method, particles size is affected by molecular weight of the macromonomer, the concentration of monomer, the composition of solvent and the ratio of hydrophobic monomer to hydrophilic macromonomer in the feed. In addition, also the particle size affected by polymerization conditions, such as the concentration of initiator, polymerization time and temperature. ${ }^{11,12}$ The surfaces of nanospheres accumulate hydrophilic components of the graft copolymers, supported by the results of electron spectroscopy for chemical analysis (ESCA). ${ }^{2-4}$ Very recently, direct observation was made of the internal structure of nanospheres prepared by the macromonomer method. ${ }^{13}$ Cross-section of the nanospheres sliced with a microtome were observed by transmission electron micrography (TEM). The analysis showed that these nanospheres have core-co- rona structures, and the thickness of the corona layer depends on molecular weight of the PEG macromonomer.

The composition of a polymeric nanosphere can be determined by ${ }^{1} \mathrm{H}$ NMR analysis, and the corona layer was confirmed by visual observation of the cross-sections by TEM. It was difficult to determine phase structures in the nanospheres from this analysis alone.

DSC reveals the thermophysical properties of solidstate bulk polymers. Physicochemical parameters such as glass transition temperature reflect the phase condition of the polymers. The structures of bulk polymers can be clarified by DSC analysis. ${ }^{14^{-16}} \mathrm{~S}$. Fu et al. ${ }^{17}$ reported that polystyrene nanoparticles prepared by microemulsion polymerization have highly-packed structures based on the thermal analysis of polystyrene nanoparticles.

This study clarifies the internal structures and thermal properties of nanospheres prepared by the macromonomer method using DSC and TEM. The morphology of core-corona nanospheres composed of poly(styrene-co-PEG macromonomer) copolymers can be clarified by the measurement of characteristic parameters such as the glass transition temperature $\left(T_{\mathrm{g}}\right)$ of polystyrene and the melting temperature $\left(T_{\mathrm{m}}\right)$ of poly(ethylene glycol).

\section{EXPERIMENTAL}

\section{Materials}

Methacryloyl group terminated poly(ethylene glycol)

\footnotetext{
${ }^{\dagger}$ To whom correspondence should be addressed (Tel: +81-99-285-8320, Fax: +81-99-255-1229, E-mail: akashi@apc.kagoshima-u.ac.jp).
} 
(PEG) $\left(M_{\mathrm{n}}=1740,4250\right)$ (PEG 1740, PEG 4250) was donated by Nippon Oil and Fats Co. (Tokyo, Japan). Styrene (Wako Pure Chemical Ind.) was purified by distillation under reduced pressure . $N, N^{\prime}$ Azobisisobutyronitrile (AIBN) (Wako Pure Chemical Ind.) was recrystallized from acetone.

\section{Preparation of Poly(styrene-co-PEG macromonomer) nanospheres}

The method for preparing poly(styrene-co-PEG macromonomer) nanospheres using methacryloyl PEG has been reported. ${ }^{1-3}$ Methacryloyl PEG, as a macromonomer, and styrene were weighted into a glass tube, together with AIBN as initiator and $5 \mathrm{~mL}$ of ethanol/ water $(4 / 1, \mathrm{v} / \mathrm{v})$ as solvent. The solution was degassed by freeze-thaw cycles on a vacuum line. The tube was sealed off and placed in a water bath at $60^{\circ} \mathrm{C}$ for $24 \mathrm{~h}$ with shaking (Scheme 1). The products were dialyzed in methanol using a cellulose dialyzer tube to remove unreacted macromonomer and styrene. The polymer particles were dialyzed in distilled water, followed by freezedrying.

\section{Characterization of Nanospheres}

The nanosphere diameter was determined with a submicron particle analyzer (Coulter model N4SD) and transmission electron micrography (TEM) (Hitachi $\mathrm{H}-$ 7010A). Compositions of the nanospheres estimated by ${ }^{1} \mathrm{H}$ NMR (JEOL FX-400) using $\mathrm{CDCl}_{3}$ as solvent.

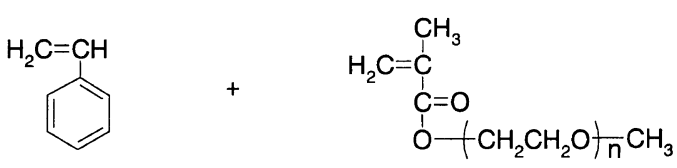

Styrene

MA-PEG macromonomer

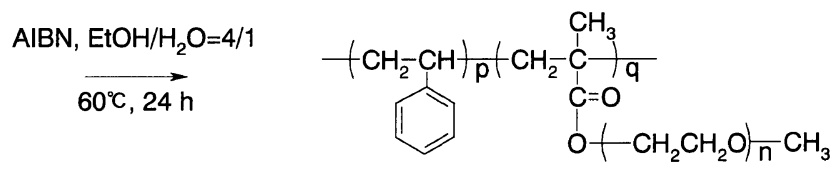

Scheme 1. Synthesis of poly(styrene-co-PEG macromonomer) nanospheres.
Annealing of Poly(styrene-co-PEG macromonomer) nanospheres

Freeze-dried nanospheres in a flask were placed under nitrogen at $60^{\circ} \mathrm{C}$ for $30 \mathrm{~min}$. The nanospheres were cooled to room temperature by liquid nitrogen. The thermal behavior of the nanospheres was examined by differential scanning calorimetry (DSC).

\section{DSC Analysis}

Differential scanning calorimetry (DSC) measurements were performed using the EXSTAR 6000 system (Seiko Instruments Inc.). Data processing was carried out using the software furnished by the manufacturer. The samples were introduced into the DSC at room temperature, followed by cooling to below -30 at $10^{\circ} \mathrm{C} \mathrm{min}{ }^{-1}$ and measurement 0 to $200^{\circ} \mathrm{C}$, while a nitrogen gas purge was used. After the first scan, the sample was quickly cooled down to below $-30^{\circ} \mathrm{C}$. Then a second scan was carried out.

\section{RESULTS AND DISCUSSION}

\section{Preparation of Poly(styrene-co-PEG macromonomer) Nanospheres}

Not only polymeric nanospheres prepared using a methacryloyl and vinylbenzyl terminated PEG macromonomers ${ }^{11,12}$ but also various other macromonomers, ${ }^{1,2,4}$ such as polyNIPAAm macromonomer with styrene have been reported. ${ }^{3}$ In this paper, PEG-coated PSt nanospheres were prepared in a similar fashion. Polystyrene core-PEG corona nanospheres were prepared using macromonomer method to clarify the internal structure and the thermal properties. Table I shows the results of copolymerization of styrene and methacryloyl PEG macromonomers. The relationship between the particle size and the hydrophobic monomer/hydrophilic macromonomer in the feed was the same as in previous studies. ${ }^{12}$ When the concentration of total monomer was constant, the nanosphere size increased with the monomer ratio of styrene to macromonomer. The nanosphere composition was estimated by ${ }^{1} \mathrm{H}$ NMR in $\mathrm{CDCl}_{3}$. The composition of styrene unit in the nanospheres was higher than that of the monomer ratio in the feed. The nanospheres had good water-dispersibility. The macromonomer chains accumulate on the surface of nanospheres prepared by the macromonomer method. ${ }^{2,3}$

Table I. Preparation of nanospheres by dispersion copolymerization of methacryloyl PEG macromonomer with styrene

\begin{tabular}{|c|c|c|c|c|c|c|c|c|c|c|c|c|}
\hline \multirow{2}{*}{ Run } & \multicolumn{3}{|c|}{ MA-PEG } & \multicolumn{2}{|c|}{$\mathrm{St}$} & \multirow{2}{*}{$\mathrm{St} /(\mathrm{MA}-\mathrm{PEG})^{\mathrm{a}}$} & \multicolumn{2}{|c|}{ AIBN } & \multirow{2}{*}{$\frac{\text { Yield }}{\%}$} & \multirow{2}{*}{$\frac{\mathrm{dm}^{\mathrm{b}}}{\mathrm{nm}}$} & \multirow{2}{*}{$\frac{\text { C.V. }}{\%}$} & \multirow{2}{*}{$\begin{array}{c}\text { Composition o } \\
\text { nanospheres } \\
\text { St/(MA-PEG) }\end{array}$} \\
\hline & $M_{\mathrm{n}}$ & $\mathrm{mg}$ & $\mathrm{mmol}$ & $\mathrm{mg}$ & $\mathrm{mmol}$ & & $\mathrm{mg}$ & $\mu \mathrm{mol}$ & & & & \\
\hline 1 & 1740 & 630 & 0.360 & 370 & 3.6 & 10 & 6.5 & 40 & 67 & 71 & 8 & 16 \\
\hline 2 & 1740 & 460 & 0.260 & 540 & 5.2 & 20 & 9.0 & 55 & 76 & 110 & 17 & 40 \\
\hline 3 & 1740 & 360 & 0.200 & 640 & 6.2 & 30 & 10.0 & 64 & 43 & 150 & 17 & 57 \\
\hline 4 & 1740 & 250 & 0.140 & 750 & 7.2 & 50 & 12.0 & 73 & 83 & 170 & 8 & 95 \\
\hline 5 & 1740 & 140 & 0.082 & 860 & 8.2 & 100 & 14.0 & 83 & 90 & 280 & 14 & 240 \\
\hline 6 & 1740 & 53 & 0.030 & 950 & 9.1 & 300 & 15.0 & 91 & 78 & 690 & 10 & 930 \\
\hline 7 & 4250 & 800 & 0.190 & 200 & 1.9 & 10 & 3.4 & 21 & 59 & 45 & 24 & 17 \\
\hline 8 & 4250 & 670 & 0.160 & 330 & 3.2 & 20 & 5.5 & 33 & 61 & 86 & 21 & 36 \\
\hline 9 & 4250 & 580 & 0.140 & 420 & 4.1 & 30 & 6.9 & 42 & 70 & 140 & 18 & 55 \\
\hline 10 & 4250 & 450 & 0.110 & 550 & 5.3 & 50 & 8.9 & 54 & 59 & 180 & 26 & 95 \\
\hline 11 & 4250 & 290 & 0.068 & 710 & 6.8 & 100 & 11.0 & 69 & 72 & 210 & 19 & 180 \\
\hline 12 & 4250 & 120 & 0.028 & 880 & 8.5 & 300 & 14.0 & 85 & 84 & 310 & 23 & 60 \\
\hline
\end{tabular}

${ }^{a}$ Styrene/methacryloyl PEG in feed. ${ }^{\mathrm{b}} \mathrm{dm}=$ Particle diameter. $\quad{ }^{\mathrm{c}} \mathrm{C} . \mathrm{V} .=$ coefficient variation. ${ }^{\mathrm{d}}$ Estimated $^{\mathrm{l}} \mathrm{H} \mathrm{NMR}$ in $\mathrm{CDCl}{ }_{3}$. 


\section{DSC Analysis}

The thermal behavior of poly(styrene-co-PEG macromonomer) nanospheres shown in Figure 1 was examined in DSC scans. Figures 1a and 1c show the first DSC profiles, and Figures $1 \mathrm{~b}$ and $1 \mathrm{~d}$ show the second scans of these nanospheres. All the samples were scanned from 0 to $200^{\circ} \mathrm{C}$ for the first scan. In all measurements, DSC curves had large endothermic peaks and change in specific heat was small. A large endothermic peak was observed between approximately 30 and $50^{\circ} \mathrm{C}$. Since melting point of methacryloyl PEG $\left(M_{\mathrm{n}}=1740,4250\right)$ was appeared at $42,53{ }^{\circ} \mathrm{C}$, respectively, we thought that the large endothermic peak on DSC scans may be attributed to the melting point $\left(T_{\mathrm{m}}\right)$ of PEG macromonomer chains that formed the nanospheres. Small change in specific heat was observed between 90 and $100^{\circ} \mathrm{C}$. The glass transition temperature $\left(T_{\mathrm{g}}\right)$ of original polystyrene was between 90 and $100^{\circ} \mathrm{C}$, depending on molecular weight of polystyrene and conditions of measurement. Figure 2 shows change in $T_{\mathrm{g}}$ and $T_{\mathrm{m}}$ of the nanospheres. The dependency of the $T_{\mathrm{m}}$ of PEG and the $T_{\mathrm{g}}$ of poly(styrene-coalkylmethacrylate) on the nanosphere composition varied based on the molecular weight of PEG consisting nanospheres. $T_{\mathrm{m}}$ of PEG in the nanospheres was lower than that of the methacryloyl PEG macromonomer. $T_{\mathrm{m}}$ of grafted PEG is lower than that of original PEG. ${ }^{16,18}$ When using PEG 4250 as the macromonomer, the $T_{\mathrm{m}}$ of PEG and the $T_{\mathrm{g}}$ of poly(styrene-co-alkylmethacrylate) were constant, even though the compositions of graft copolymers were different. Using PEG 1740, the $T_{\mathrm{m}}$ of PEG and the $T_{\mathrm{g}}$ of poly(styrene-co-alkylmethacrylate) were dependent on the compositions of the graft copolymer. Low purity bulk polymers may thus have lower than expected $T_{\mathrm{g}}$ value. ${ }^{19,20}$ Dependency of $T_{\mathrm{m}}$ and $T_{\mathrm{g}}$ on compositions of the graft copolymers of poly(styrene-coPEG macromonomer) nanospheres means that phases
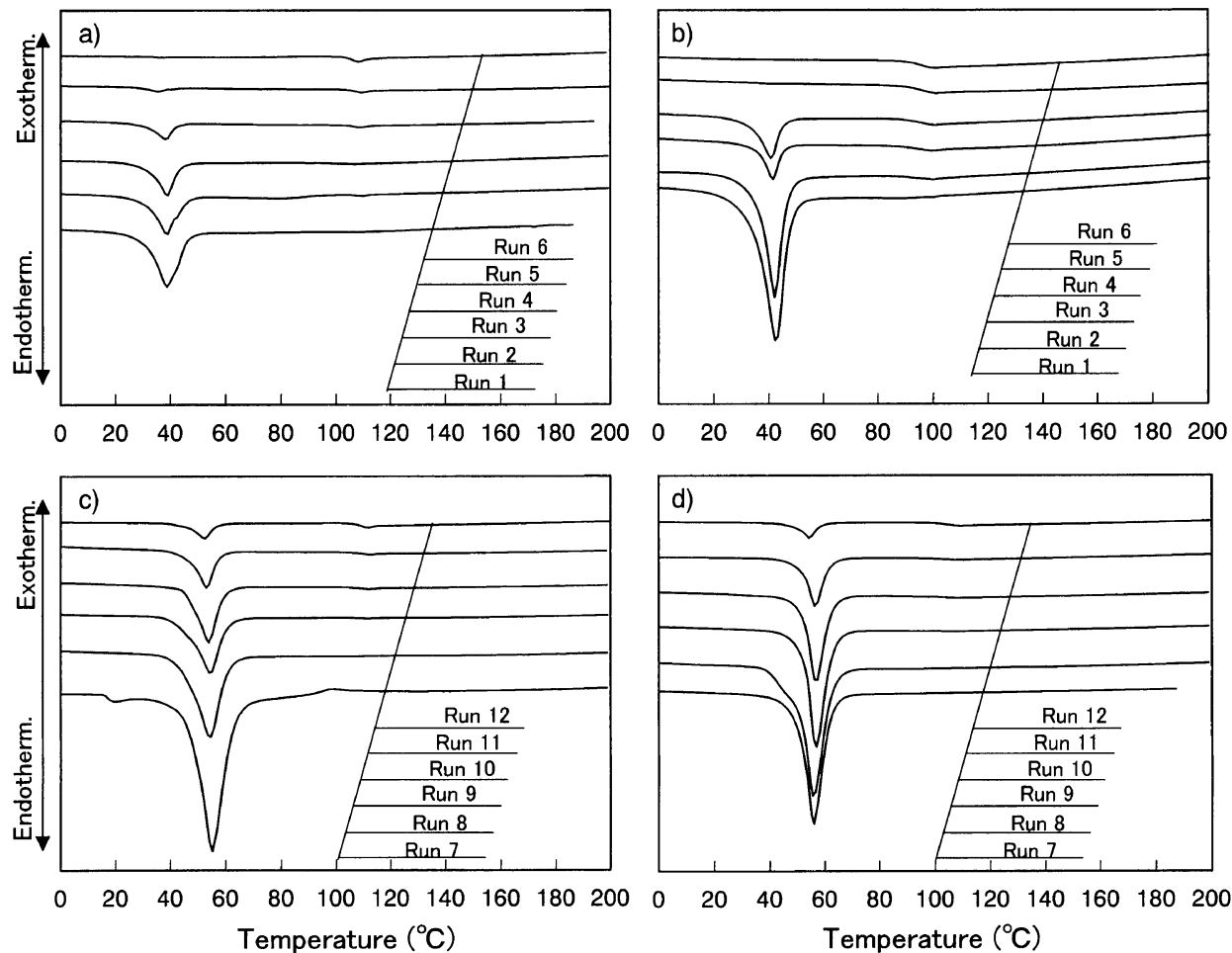

Figure 1. DSC curves of nanospheres composed of graft copolymers. a) The first scan, b) The second scan of nanospheres containing PEG 1740. c) The first scan, d) The second scan of nanospheres containing PEG4250.
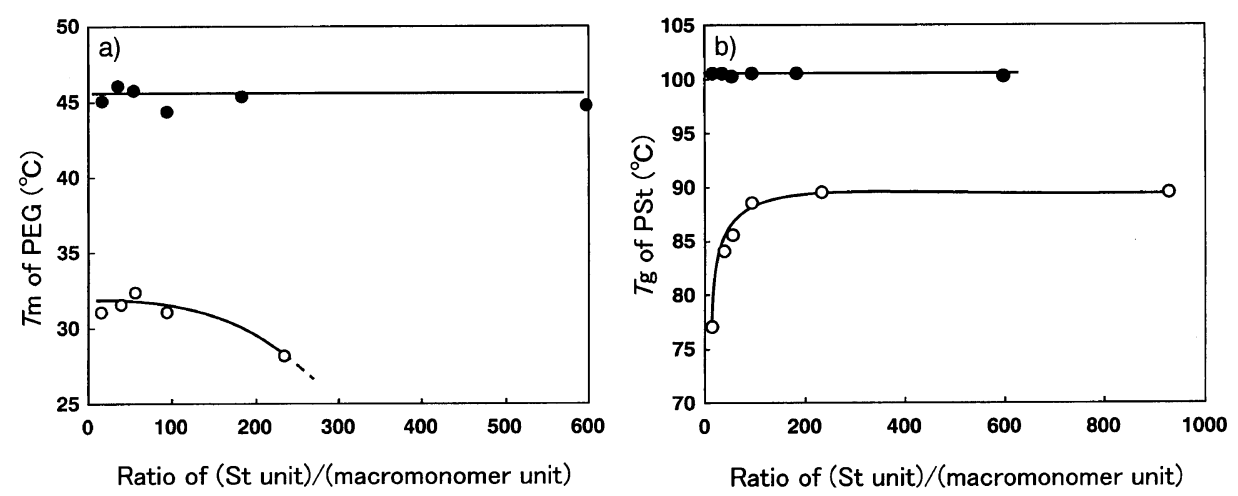

Figure 2. Changes in a) $T_{\mathrm{m}}$ attributed to the PEG components of nanospheres, and b) $T_{\mathrm{g}}$ attributed to the poly(styrene-coalkylmethacrylate) components of the nanospheres. (O) The nanospheres containing PEG1740,

The nanospheres containing PEG4250. 
become mixed. The $T_{\mathrm{m}}$ of PEG phase of runs $1-4$ was around $32^{\circ} \mathrm{C}$. The $T_{\mathrm{m}}$ of PEG phase of run 5 was found at around $27^{\circ} \mathrm{C}$. In the case of run 6 , the $T_{m}$ of the PEG phase of nanospheres was not detected. The distribution of PEG in the nanospheres is thus affected by the composition of the graft copolymers. In the case of runs $1-4$, PEG as a side chain in the graft copolymer was enough to demonstrate its melting point. There was little PEG in the nanospheres in runs 5 and 6 . The melting point of PEG macromonomer in the nanosphere was not observed by DSC. The changes in the $T_{\mathrm{g}}$ attributed to poly(styrene-co-alkylmethacrylate) phase in nanospheres are plotted in Figure $2 \mathrm{~b}$. The nanospheres with high poly(styrene-co-alkylmethacrylate) content showed glass transition at around $90^{\circ} \mathrm{C}$ (runs 5 and 6 ). The glass transition temperature reflects the purity of the polymer. The $T_{\mathrm{g}}$ of the nanospheres with high PEG content (runs 1-4) was lower. Possibly, due to the interactions of the poly(styrene-co-alkylmethacrylate) phases with the PEG forming side chains on the graft copolymer.

Heat released by PEG can be calculated from DSC. Theoretical heat of melting PEG can be calculated from the nanosphere composition estimated by ${ }^{1} \mathrm{H}$ NMR (Table I). Theoretical melting calorie $\left(\Delta H_{\text {cal }}\right)$ was calculated by the DSC of methacryloyl PEG macromonomer as $185.7 \mathrm{~J} \mathrm{~g}^{-1}$. This value was different from $\Delta H$ of PEG (molecular weight is $200000, \Delta H=155.6 \mathrm{~J} \mathrm{~g}^{-1}$ ). ${ }^{18} \mathrm{It}$ was considered that the difference of $\Delta H$ was affected from the molecular weight and terminated group of the polymers. PEG phase in nanospheres was studied by examining the gap between the two values. Figure 3 shows the correlation between the heat from PEG as it melted and the heat based on the nanosphere composition. All experimental $\Delta H_{\text {exp }}$ were less than $\Delta H_{\text {cal }}$. This suggests that some of the PEG in the nanospheres is mixed in the poly(styrene-co-alkylmethacrylate) phase. The differences between actual and predicted heat values were higher for nanospheres prepared using PEG 1740 than nanospheres prepared using PEG 4250. This is supported by the fact that the compatibility of PEG and poly(styrene-co-alkylmethacrylate) is dependent on the molecular weight.

\section{Annealing on Poly(styrene-co-PEG macromonomer) Nanospheres}

The morphology and physical properties of copolymer and polymer blend are easily affected by heat history. Recently, it was reported by several researchers that the morphology of glassy polymer such as polystyrene changes by relaxation of enthalpy, although less than $T_{\mathrm{g}}$ of oneself. ${ }^{21}$ Figure 4 shows TEM of annealed nanospheres (runs 3 and 5 , Table I) under nitrogen at $60^{\circ} \mathrm{C}$ for $30 \mathrm{~min}$. The morphology of the nanospheres in run 5 $(\mathrm{dm}=c a .280 \mathrm{~nm})$ was not changed by this treatment. In run $3(\mathrm{dm}=c a .150 \mathrm{~nm})$, the nanospheres coalesced. Nanospheres containing high PEG content had lower $T_{\mathrm{g}}$ than those containing relatively little PEG. DSC scans of nanospheres (run 5) before and after annealing are shown in Figure 5. DSC curves in the first scan were almost the same in shape. In the second scan, DSC curve shapes were different. Using nanospheres not treated, heat released due to PEG melting in first scan could barely be detected in the second scan. Using nano-

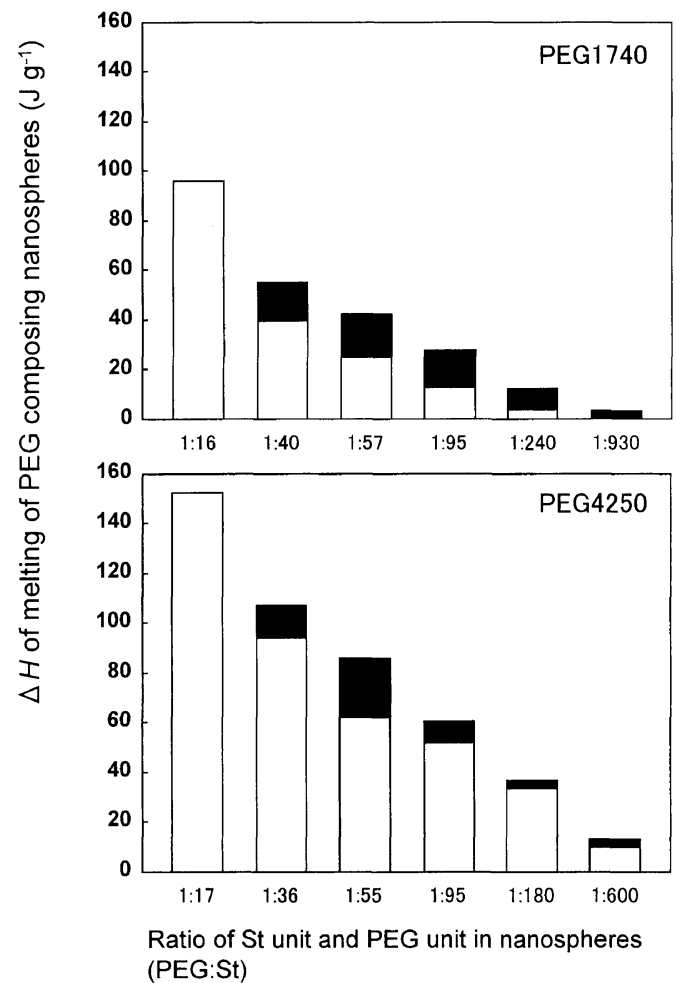

Figure 3. Endothermic heat due to PEG melting correlated with that predicted by the nanosphere composition. Opened bar indicates the heat measured by DSC $\left(\Delta H_{\text {exp }}\right)$, and the height of the bar $\left(\Delta H_{\text {cal }}\right)$ indicates the heat predicted based on the composition estimated by ${ }^{1} \mathrm{H}$ NMR. Closed bar shows the difference between the two values.

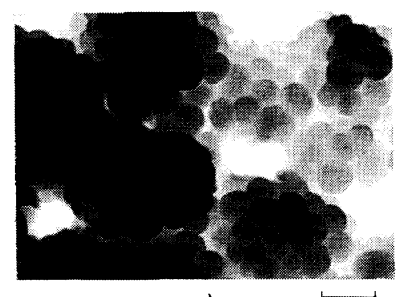

a)

$300 \mathrm{~nm}$

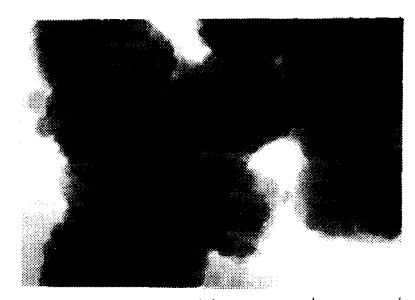

b)

$\stackrel{100 \mathrm{~nm}}{ }$
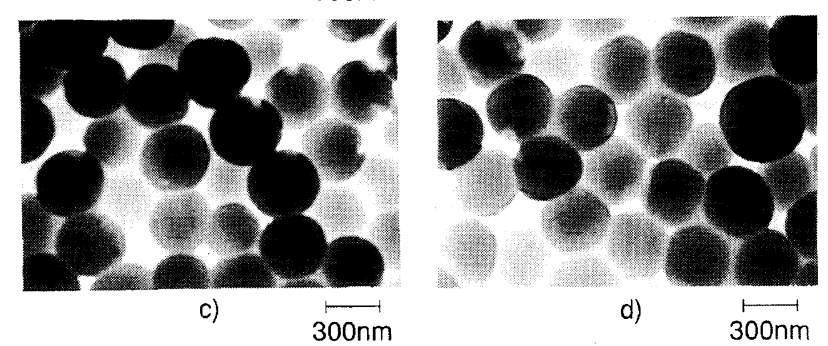

Figure 4. Changes in the morphology of nanospheres with heat treatment at $60^{\circ} \mathrm{C}$ for $30 \mathrm{~min}$. a) Run $3(\mathrm{dm}=c a .150 \mathrm{~nm})$ before annealing, b) Run 3 after annealing, c) Run $5(\mathrm{dm}=c a .280 \mathrm{~nm})$ before annealing, d) Run 5 after annealing.

spheres after annealing, the amount of heat released from PEG melting in the second scan was higher than in the first scan. $T_{\mathrm{g}}$ attributed to poly(styrene-coalkylmethacrylate) in the second scan was higher than in the first scan. Thermal properties of the nanospheres drastically changed by mild heat treatment, even though shape of the nanospheres was not affected. These results suggest that the internal phase structure of nanospheres 

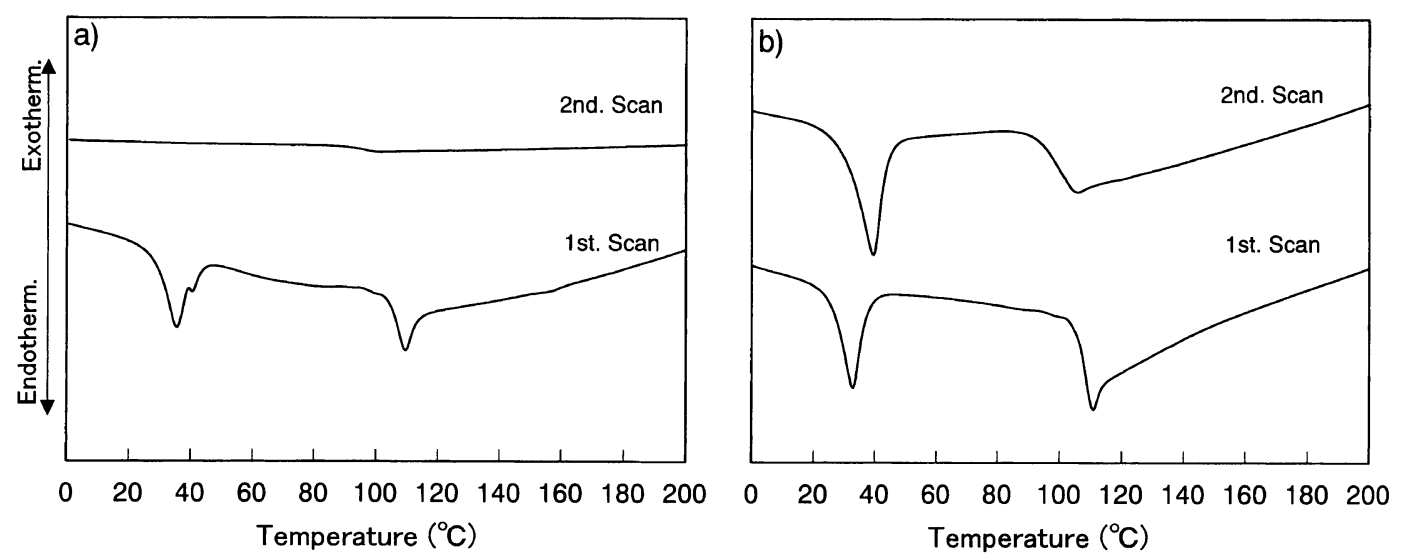

Figure 5. Effects of heat treatment on the DSC curves of nanospheres. a) Untreated nanospheres, b) Nanospheres treated with heat.

may thus be affected by heat treatment at $60^{\circ} \mathrm{C}$ for 30 min. Poly(styrene-co-alkylmethacrylate) phase in nanospheres may possibly be involved with the PEG macromonomer depending on the composition.

\section{CONCLUSION}

Internal structures of core-corona nanospheres prepared by the copolymerization of PEG macromonomers with styrene using DSC thermal analysis were studied. Two characteristic peaks in DSC curves were attributed to the components of nanosphere. And, the two peaks were thought to correspond to the graft copolymer phase-separated poly(styrene-co-alkylmethacrylate) and the PEG phases in the nanospheres. Heat released from melting for the nanospheres composed of PEG was smaller than expected based on theoretical values. The ratio of the mixed PEG to the poly(styrene-coalkylmethacrylate) phase depended on the molecular weights of the component. The thermophysical properties of poly(styrene-co-PEG macromonomer) nanospheres changed by a mild heat treatment, even when the nanosphere shape was not affected. Core-corona polymeric nanospheres prepared by the macromonomer method exist the meta-stable state, after freeze-drying treatment. The annealing of nanospheres stimulates clear phase-separation in hydrophobic core to give a thermally stable state in final. Some PEG in the nanospheres may thus be mixed in the poly(styrene-coalkylmethacrylate) phase, in which is core of nanosphere. This may possibly explain the structures of the core-corona polymeric nanosphere. The findings in this study should be helpful for understanding the properties of core-corona nanospheres prepared by the macromonomer method.

Acknowledgment. We acknowledge Terumi Kakoi, Kagoshima University, for the assistance in obtaining TEM data. K. Hiwatari is indebted to Japan Science for the Promotion of Science (JSPS Research Fellowships for Young Scientist) for a research grant.

\section{REFERENCES}

1. M. Akashi, I. Kirikihira, and N. Miyauchi, Angew. Makromol. Chem., 132, 81 (1985).

2. M. Riza, S. Tokura, A. Kishida, and M. Akashi, New Polymeric Mater., 4(3), 189 (1994).

3. M.-Q. Chen, A. Kishida, and M. Akashi, J. Polym. Sci., Part A: Polym. Chem., 34, 2213 (1996).

4. M. Riza, S. Tokura, M. Iwasaki, E. Yashima, A. Kishida, and M. Akashi, J. Polym. Sci., Part A: Polym. Chem., 33, 1219 (1995).

5. C.-W. Chen, T. Serizawa, and M. Akashi, Langmuir, 15, 7998 (1999).

6. M. Akashi, T. Niikawa, T. Serizawa, T. Hayakawa, and M. Baba, Bioconjug. Chem., 9, 50 (1998).

7. S. Sakuma, N. Suzuki, H. Kikuchi, K. Hiwatari, K. Arikawa, A. Kishida, and M. Akashi, Int. J. Pharm., 149, 93 (1997).

8. S. Sakuma, N. Suzuki, H. Kikuchi, K. Hiwatari, K. Arikawa, A. Kishida, and M. Akashi, Int. J. Pharm., 158, 69 (1997).

9. S. Sakuma, Y. Ishida, R. Sudo, N. Suzuki, H. Kikuchi, K. Hiwatari, A. Kishida, M. Akashi, and M. Hayashi, Int. J. Pharm, 159, 181 (1997).

10. T. Serizawa, M.-Q. Chen, and M. Akashi, J. Polym. Sci., Part A: Polym. Chem., 36, 2581 (1998).

11. M. Q. Chen, A. Kishida, T. Serizawa, and M. Akashi, J. Polym. Sci., Part A: Polym. Chem., 38, 1811 (2000).

12. M.-Q. Chen, T. Serizawa, A. Kishida, and M. Akashi, J. Polym. Sci., Part A: Polym. Chem., 37, 2155 (1999).

13. T. Serizawa, S. Takehara, and M. Akashi, Macromolecules, 33, 1759 (2000).

14. T. G. Mahr, J. Phys. Chem., 74(10), 2160 (1970).

15. U. Gaur and B. Wunderlich, Macromolecules, 13, 1618 (1980).

16. N. Uyanik and B. M. Baysal, J. Appl. Polym. Sci., 41, 1981 (1990).

17. W. Ming, J. Zhao, X. Lu, C. Wang, and S. Fu, Macromolecules, 29, 7678 (1996).

18. L. Kvist, H. Bertilsson, and P. Meuller, Polym. Eng. Sci., 38, 1303 (1998).

19. M. C. Chen and A. Eisenberg, "Progress in Solid State Chemistry", H. Reiss, Ed., Pergamon Press, Oxford, 1966, vol. 3, p 407; reprint in Rubber Chem. Technol., 43, 156 (1970).

20. G. Allen, J. McAinsh, and G. M. Jeffs, Polymer, 12, 85 (1971).

21. J. L. G. Ribelles and M. M. Pradas, Macromolecules, 28, 5867 (1995). 